\title{
Article \\ The Impact of Temporary Means of Access on Buildings Envelope's Maintenance Costs
}

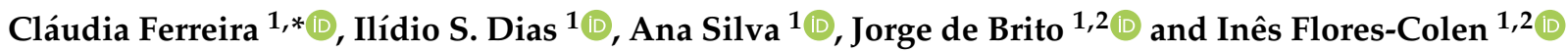 \\ 1 CERIS, Instituto Superior Técnico, Universidade de Lisboa, Av. Rovisco Pais, 1049-001 Lisboa, Portugal; \\ ilidio.dias@tecnico.ulisboa.pt (I.S.D.); ana.ferreira.silva@tecnico.ulisboa.pt (A.S.); jb@civil.ist.utl.pt (J.d.B.); \\ ines.flores.colen@tecnico.ulisboa.pt (I.F.-C.) \\ 2 Department of Civil Engineering, Architecture and Georesources, Instituto Superior Técnico, Universidade de \\ Lisboa, Av. Rovisco Pais, 1049-001 Lisboa, Portugal \\ * Correspondence: claudiaarferreira@tecnico.ulisboa.pt
}

check for updates

Citation: Ferreira, C.; Dias, I.S.; Silva, A.; de Brito, J.; Flores-Colen, I. The Impact of Temporary Means of Access on Buildings Envelope's Maintenance Costs. Buildings 2021, 11, 601. https://doi.org/10.3390/ buildings11120601

Academic Editor: David Arditi

Received: 27 October 2021

Accepted: 26 November 2021

Published: 1 December 2021

Publisher's Note: MDPI stays neutral with regard to jurisdictional claims in published maps and institutional affiliations.

Copyright: (c) 2021 by the authors. Licensee MDPI, Basel, Switzerland. This article is an open access article distributed under the terms and conditions of the Creative Commons Attribution (CC BY) license (https:/ / creativecommons.org/licenses/by/ $4.0 /)$.

\begin{abstract}
Accessibility to buildings' envelope depends on efficient inspection and other maintenance actions of their components. When access to these components is not planned, special means of access are required to carry out the maintenance work. Means of access, besides having a fundamental role on the quality of maintenance works of building envelope components, also represents a considerable part of the maintenance costs. Thus, to optimize costs and resources in maintenance plans, assessment of the impact of the means of access on maintenance costs is crucial. For works in height, there are several alternative means of access. The choice of the most adequate solution is strongly linked to the characteristics (e.g., architecture, height) and constraints (e.g., users, surrounding space) of each building, the maintenance needs of the envelope, and the time and funds available for the intervention. Therefore, in this study, a sensitivity analysis to understand how the cost of means of access can influence the maintenance costs is carried out. Moreover, the optimisation of maintenance activities in façade claddings is also analysed. This study intends to assess whether it is advantageous to consider permanent means of access during the design phase or opt for temporary means of access. In a first stage, the impact of six temporary means of access (supported and suspended scaffolds; articulated booms; telescopic booms; scissor lifts; and rope access) on the maintenance plans developed for the six types of claddings (ceramic tiling systems-CTS, natural stone claddings-NSC, rendered façades-RF, painted surfaces-PS, external thermal insulation composite systems-ETICS, and architectural concrete façades-ACF) is examined. The impact is estimated through a stochastic maintenance model based on Petri nets. After that, a sensitivity analysis and a multi-criteria decision analysis are performed. Based on the results, general recommendations are presented concerning the maintenance strategies to adopt in the cladding solutions analysed. The results reveal that planning the means of access during the design stage can be economically beneficial for all buildings' envelope components.
\end{abstract}

Keywords: degradation; maintenance; façade claddings; means of access

\section{Introduction}

In the building management field, an adequate degradation condition can be easily achieved but maintaining this degradation condition over time is another matter. Regular inspections and maintenance interventions are fundamental to preserve the degradation state of the building components, whatever their size, complexity, or function [1]. Accessibility is one of the main barriers to maintenance. While there are building envelope components that are easily accessible (e.g., windows frames or even roofs), external façades usually require special means of access to carry out the maintenance works [2]. Furthermore, these are not commonly designed to provide safe access to maintenance workers. In the construction sector, works in height are probably the activities that more frequently require special means of access [3]. 
In buildings, accessibility to all components, for maintenance activities, should be a concern of stakeholders at the design phase [4]. For example, the external façades of buildings should be designed by considering safe and easy access of the maintenance staff. The shape of the surface and number of features influence how the façade can be accessed [1]. Not planning assets with adequate means of access (permanent and/or temporary) is usually translated into higher maintenance costs, since temporary means of access need to be used to overcome this limitation and are not usually predicted in maintenance costs planning [5]. In the literature, there are no research studies that quantify the economic impact of temporary means of access during the service life of building components. Moreover, globally, the number of studies in the literature that deal with maintenance costs [6], the cost of the different types of inspections/maintenance of buildings [7], or the difference between what is planned and what is spent [8] is quite low. Concerning accessibility, the studies only suggest that this impact is real and significant to put into practice maintenance strategies during the life cycle. For example, according to the Construction Industry Institute (CII), temporary facilities for access are one of the main categories that influence the indirect construction costs [9]. El-Haram and Horner [10], in a study about the factors that affect maintenance costs, refer that, to reduce the maintenance costs, the number and/or the duration of the maintenance activities must be reduced. The authors also assert that the duration of the maintenance activities can be reduced by increasing the accessibility and planning maintenance resources. Moreover, Ferreira et al. [11] suggest that the fixed costs, namely the means of access, have a considerable influence on maintenance costs and, consequently, on the choice of maintenance strategies. In terms of safety, from a study about the implementation of design solutions to improve safety on the construction site during the construction stage in roofs, it is understood that permanent solutions are more expensive than temporary solutions [12]. However, in this study, the exploration stage is not considered. Still, from the findings of Rajendran and Gambatese [12], it is assumed that, when maintenance is really implemented in buildings during the life cycle, there are advantages in choosing the permanent solutions. The high initial costs of these solutions can be amortized over the years because there are no expenses with the non-predicted temporary means of access.

\section{Methodology}

In this study, a sensitivity analysis to understand how the cost of the means of access can influence the maintenance costs is carried out. The optimisation of maintenance activities in façade claddings is also analysed. This research intends to assess whether it is advantageous to consider permanent means of access during the design phase or to opt for predicted temporary means of access. To do that, in a first step, a stochastic maintenance model based on Petri nets is used to assess the impact of different temporary means of access in the maintenance plans developed for different types of claddings is examined. Six temporary means of access (supported and suspended scaffolds, articulated booms, telescopic booms, scissor lifts, and rope access) and six façade claddings (ceramic tiling systems - CTS, natural stone claddings-NSC, rendered façades- RF, painted surfacesPS, external thermal insulation composite systems-ETICS, and architectural concrete façades-ACF) are analysed. These equipment types are chosen because they are the most common in Portugal. In a second phase, a sensitivity analysis is performed to analyse how the different façade claddings' maintenance strategy costs are influenced by the cost of the means of access, and a multi-criteria decision analysis is carried out to analyse the more beneficial alternatives. Furthermore, based on the results obtained in the multicriteria analysis, general recommendations are presented for the maintenance strategies. In this study, only the cumulative average costs of maintenance plans are considered. As a simplification, it is assumed that both the impact of the different maintenance activities on the degradation state and the time intervals between inspections are not influenced by the means of access selected. 


\section{Means of Access}

Means of access are assemblies/structures or equipment used to provide support to people and material during the construction and/or maintenance of the building elements, at heights above the ground, allowing activities to be carried out under safe conditions [13]. According to its nature, the means of access are classified in two types [14]: permanent and temporary. Although permanent access systems can be implemented during the operational stage of the buildings, these systems are usually planned during the design stage and implemented at the construction stage [14]. Since the main purpose of these systems is aiding the periodic maintenance of building, they should be designed to facilitate access of the maintenance personnel to the building envelope, as well as to cover the largest possible area of the façade without causing damage to it, when the system is being used [15]. These systems are generally applied in buildings where maintenance requirements are high (for example, glass façade). There are several solutions for permanent access systems [14], depending on the buildings' characteristics (architecture, height, among others) and constraints of each building (users, surrounding space, among others), the maintenance needs of the façade, and the time and funds available for the intervention [16].

On the other hand, temporary access systems are only installed before inspections or maintenance interventions take place and are removed after completion of the actions. This type of access system is used in two situations: when buildings do not have permanent means of access or when have permanent means of access, but these means are not able to cover all the singular points that need maintenance. As for permanent access systems, there are a variety of solutions for temporary access systems and its choice must take into account the characteristics and constraints of each building [16]. Among them are supported and suspended scaffolds, aerial work platforms (articulated booms, telescopic booms, and scissors lifts), and rope access (Figure 1). The temporary access systems represented in Figure 1 illustrate the means of access most often used in maintenance activities in current buildings.

\subsection{Supported Scaffolds}

Supported scaffolds are considered the means of access most used in building maintenance [5], as seen in Figure 1a. Scaffolding consists of a set of horizontal platforms, at different levels, linked by ladders and shoring props. In terms of disadvantages, to guarantee the safety, the temporary structure needs anchorage points. If the façade does not contemplate these points, the surface can be damaged. In addition, supported scaffolds require space and suitable ground to be installed [5]. Finally, the assembly and disassembly have a considered impact on the labour cost and construction schedule [9].

\subsection{Suspended Scaffolds}

Suspended scaffolds, as seen in Figure 1b, consist of a platform, rigging to suspend the platform, a hoist to move it up and down, and an anchor for the suspension ropes $[17,18]$. This equipment is provisionally suspended from the roof, and it is normally used in maintenance operations in high-rise buildings [18]. The choice of this equipment must consider the weather conditions (namely the action of the wind) and the characteristics of the roof. By comparison with the supported scaffolds, the assembly and disassembly times are shorter, it has a good carrying capacity for people and materials, and it allows access to façades with restrictions at the soil level [19], but it has limitations in complex features and protrusions from the façade [2]. 


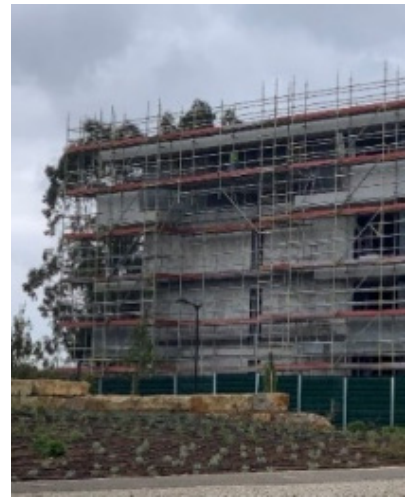

(a)

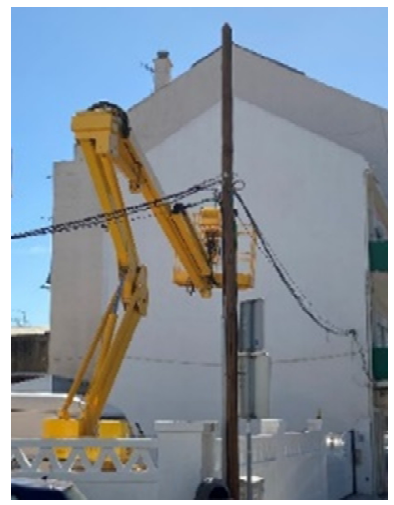

(d)

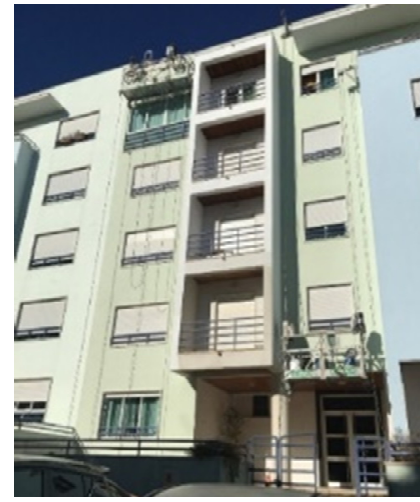

(b)

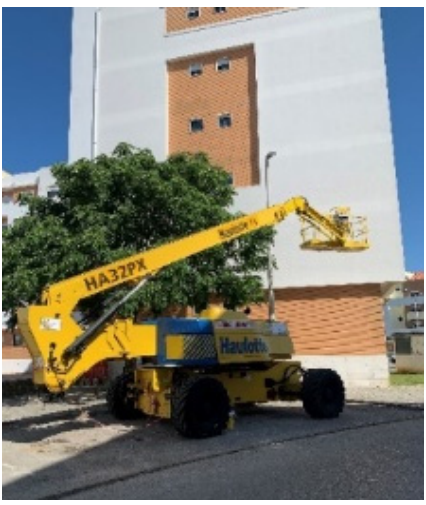

(e)

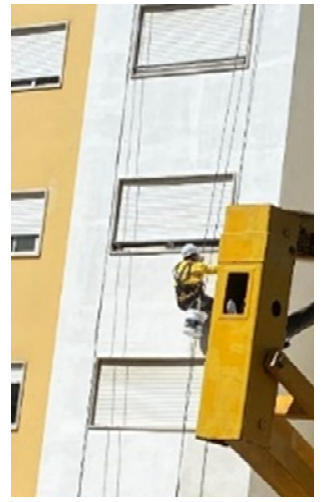

(c)

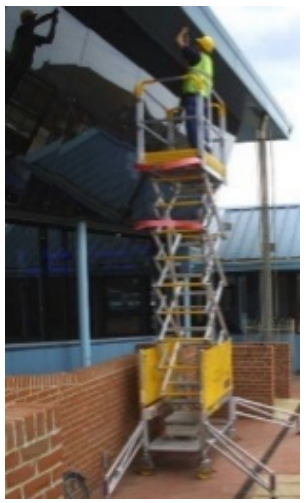

(f)

Figure 1. Illustrative examples of the different temporary means of access: (a) supported scaffolds; (b) suspended scaffolds; (c) rope access; (d) articulated booms; (e) telescopic booms; (f) scissor lifts.

\subsection{Rope Access}

Compared to other means of access [5,20], rope access (Figure 1c) provides easy access to all areas of the façade, ensures quick installation, and requires little equipment. Furthermore, the visual impact on the building is reduced and it does not need to damage the cladding to work on the façade [20]. On the other hand, the workers need specific training [20], and it is uncomfortable for long-term works [2,16]. The application of rope access ensures that the building meets adequate conditions for the installation of anchorage points. Moreover, good weather conditions should be assured during the intervention on the façade. The use of this technique can also jeopardize the quality of the maintenance work, thus this technique is mainly used for light maintenance actions and surveying $[5,21]$.

\subsection{Aerial Work Platforms}

In terms of aerial work platforms, articulated booms (Figure 1d), telescopic booms (Figure 1e), and scissor lifts (Figure 1f) are the most common. Aerial work platforms are motorised vehicles and have reduced installation times. However, the weather conditions can also influence the performance and safety of this means of access, particularly the incidence of wind. Moreover, the ground surrounding the façade should have sufficient strength to support the equipment [14]. The work platform of the articulated and telescopic booms extends (vertical and horizontal) beyond the wheelbase of the supporting structure while scissor lifts are elevating platforms (only with vertical movement) [22]. These means of access are normally used in occasional and short-term maintenance operations in low-tomedium-height buildings. The reach of these equipment types is reduced when compared with the other means of access (approximately $20 \mathrm{~m}$ to articulated and telescopic booms, and $10 \mathrm{~m}$ to scissor lifts) $[17,22]$. 


\section{Materials and Methods}

To understand the influence of the means of access on the maintenance costs of building envelope elements, six temporary access systems are analysed: (i) supported scaffolds; (ii) suspended scaffolds; (iii) articulated booms; (iv) telescopic booms; (v) scissor lifts; and (vi) rope access.

\subsection{Costs of Means of Access to Maintain the Building Envelope}

Table 1 presents the costs of the different means of access analysed. These are average costs in Portugal, which were obtained through consultation with companies in this area of expertise from May to July 2020. As a case study, it was assumed that the equipment would be needed to intervene a $250 \mathrm{~m}^{2}$ façade cladding.

Table 1. Unit cost, at year 0, for the different means of access.

\begin{tabular}{ccccccc}
\hline \multirow{2}{*}{ Means of Access } & \multirow{2}{*}{$\begin{array}{c}\text { Supported } \\
\text { Scaffolds }\end{array}$} & \multicolumn{3}{c}{ Aerial Work Platform } & \multirow{2}{*}{$\begin{array}{c}\text { Suspended } \\
\text { Scaffolds }\end{array}$} & Rope Access \\
\cline { 3 - 5 } & 10.20 & 8.13 & 11.84 & 10.58 & 4.68 & 2.12 \\
\hline Costs $\left(€ / \mathrm{m}^{2}\right)$ & 10.20 & Articulated Boom & Telescopic Booms & Scissor Lifts & \\
\hline
\end{tabular}

Rope access is the means of access with the lowest cost $\left(2.12 € / \mathrm{m}^{2}\right)$. This means of access is suitable for cleaning operations on façades and possibly for more occasional minor interventions, considering the type of coating to be intervened. For example, this technique has been used in total replacement of the coating in painted surfaces. After rope access, suspended scaffolds are the most economical means of access, with an estimated value of around $4.68 € / \mathrm{m}^{2}$. Compared to rope access, this equipment has a larger working area as well as greater load capacity. Regarding aerial work platforms, articulated booms are the most economical, with an average cost of $8.13 € / \mathrm{m}^{2}$, which is lower than supported scaffolds $\left(10.20 € / \mathrm{m}^{2}\right)$. Based on that and considering the constraints of supported scaffolds, such as the times of assembly and disassembly, visual impact on the façade, among others, articulated booms can be a good alternative, particularly in minor interventions.

\subsection{Maintenance Model}

This analysis is supported by a stochastic maintenance model based on Petri nets. This model was previously developed by the authors [23], as a useful tool to analyse the trade-off between different alternatives. The maintenance model developed is a conditionbased model that, in addition to the degradation process, also includes the inspection and maintenance processes.

The classification system implemented is composed of five degradation conditions, varying between $\mathrm{A}$ (no visual degradation) and $\mathrm{E}$ (generalized degradation). The degradation condition is defined based on the severity of degradation index, $S_{w}$-Equation (1).

$$
S_{w}=\frac{\sum\left(A_{n} \times k_{n} \times k_{a, n}\right)}{A \times \sum k},
$$

where $S_{w}$, the severity of degradation (in \%), is the ratio between the area affected by the anomalies observed in the building component, weighted according to their severity, and a reference area is equivalent to the total area with the highest possible degradation level. $A_{n}$-the area affected by anomaly $n$ (in $\mathrm{m}^{2}$ ); $k_{n}$ - the multiplication factor for the anomaly $n ; k_{a, n}$-the weighting coefficient according to the relative weight of the anomaly $n$; $A$-the total area of the constructive solution (in $\mathrm{m}^{2}$ ); and $k$-the multiplying factor corresponding to the highest degradation condition of the area $A$. These parameters vary according to the constructive solution (for CTS, see [24]; for NSC, see [25]; for RF, see [26]; for PS, see [27]; for ETICS, see [28]; and, for ACF, see [29]).

In the maintenance model, interventions are divided in four levels: (i) inspections; (ii) cleaning operations; (iii) minor interventions; and (iv) total replacement. In the inspection, 
a visual assessment of the building component is carried out. In the cleaning operation, the removal of the visual anomalies (soiling, stains, and other deposits) is proceeded. In the minor intervention, in addition of the cleaning operations, localized repair and/or partial replacement are also considered. Finally, in the total replacement, the complete replacement of the building component is carried out. Since the maintenance model is condition-based, a decision of maintenance activities is taken based on the inspection diagnosis. In this case study, it is assumed that, if the degradation condition of the building component is A, no maintenance is carried out; if it is $B$, a cleaning operation is needed; if it is $C$, a minor intervention is required; and, finally, if it is D or $\mathrm{E}$, total replacement must be carried out. The outputs of the maintenance model (service life, life-cycle costs, efficiency index, and number of interventions) are used to assess the different alternatives.

\section{Sensitivity Analysis}

To analyse how the different façade claddings' maintenance strategy costs are influenced by the cost of the means of access, a sensitivity analysis is carried out. This analysis has only impact on the maintenance costs. The impact of different maintenance activities on the degradation condition of claddings as well as the time intervals between inspections are the same regardless of the means of access selected. Furthermore, in the composition of the price of maintenance activities (cleaning operations, minor interventions, and total replacement), there is only a change in the cost of the means of access. The costs of materials, equipment, and labour remain the same. Results regarding the service life, efficiency index, and number of interventions can be consulted in Ferreira et al. [30]. In this study, there are six façade claddings (CTS, NSC, RF, PS, ETICS, and ACF), and four maintenance strategies, which are analysed below.

- Maintenance strategy 1 (MS1): includes only the total replacement of the façade. This maintenance strategy is used to characterize the strategy most adopted by the owners or managers of the buildings. The façade is only intervened when the end of their service life is reached. MS1 is applied to the six claddings.

- Maintenance strategy 2 (MS2): combination of total replacement and minor interventions. The minor intervention is added to delay or mitigate the degradation process, showing that localized repairs or replacements can be carried out to increase the service life of the claddings and, consequently, to prevent unnecessary interruptions without compromising important characteristics of the claddings. MS2 is not applied to PS due to its short service life.

- Maintenance strategy 3 (MS3): combination of total replacement, minor interventions, and cleaning operations. The introduction of cleaning operations represents the maintenance activity most applied (easier and more economical) in claddings. MS3 is not applied to PS.

- Maintenance strategy 4 (MS4): combination of total replacement and cleaning operations. It is a simplification of MS3. Since PS are not subject to minor interventions, MS4 is only applied to them.

The maintenance costs over time $(C)$ include the costs of inspection $\left(C_{\text {inspection }}\right)$ and other maintenance activities $\left(C_{\text {maintenance }}\right)$ (cleaning operations, minor interventions, and total replacement) (Equation (2)).

$$
C=C_{\text {inspection }}+C_{\text {maintenance }}
$$

To consider future investments in this analysis, the net present value of the inspection and maintenance activities is computed through Equations (3) and (4) [31].

$$
C_{\text {inspection }}=\sum_{t=0}^{t_{h}} \frac{C_{\text {inspection }, 0}}{(1+v)^{t}}
$$




$$
C_{\text {maintenance }}=\sum_{t=0}^{t_{h}} \frac{C_{\text {maintenance, } 0}}{(1+v)^{t}}
$$

where $C_{\text {inspection, } 0}$ and $C_{\text {maintenance, } 0}$ are the inspection and other maintenance costs at year 0 (Tables 1 and 2), respectively; $v$ is the real discount rate; and $t_{h}$ is the time horizon. In this study, a private sector environment is considered. Therefore, a real discount rate of $6 \%$ is adopted [32,33]. Finally, a time horizon of 150 years is considered as the period of study. A long-term horizon is used to guarantee that a considerable percentage of the Monte Carlo simulation samples reach the end of the service life, in the more durable constructive solutions, allowing decreasing uncertainty in the analysis.

Table 2. Unit costs, at year 0, for the different maintenance activities without the means of access costs.

\begin{tabular}{ccccccc}
\hline & CTS & NSC & RF & PS & ETICS & ACF \\
\hline Inspection $\left(€ / \mathrm{m}^{2}\right)$ & & & & 1.03 & & \\
Cleaning operations $\left(€ / \mathrm{m}^{2}\right)$ & 17.28 & 21.17 & 16.68 & 16.68 & 16.68 & 16.98 \\
Minor interventions $\left(€ / \mathrm{m}^{2}\right)$ & 55.57 & 58.60 & 24.48 & - & 47.93 & 74.55 \\
Total replacement $\left(€ / \mathrm{m}^{2}\right)$ & 58.65 & 139.31 & 26.48 & 20.18 & 85.78 & 96.28 \\
\hline
\end{tabular}

The costs of the different maintenance activities (Table 2) are adapted from the literature [34]. Since the cost of the maintenance activities varies according to the materials applied, the following assumptions are adopted: (i) CTS-sandstone tiles; (ii) NSC-Alpinina stone; (iii) RF-current cementitious-based render; (iv) PS-paint based on acrylic polymers; (v) ETICS-expanded polystyrene boards as thermal insulation material and acrylic-based coat as finishing material; and (vi) ACF-façade cast in situ with a thickness of $25 \mathrm{~cm}$ and a smooth texture without paint. Only visual inspections are considered in this study.

According to the remarks presented in Section 3, for the six façade claddings, the following means of access are analysed: supported scaffold (the most commonly used means of access), suspended scaffolds, aerial work platforms (articulated booms, telescopic booms, and scissors lifts), and rope access. Finally, the situation in which maintenance activities can be carried out safely without the need of additional means of access is also analysed. The comparison of this situation with the different means of access helps to assess the influence of the means of access on the maintenance costs.

Regarding the maintenance strategies, for CTS, NSC, RF, ETICS, and ACF, four maintenance strategies are analysed: MS1, MS2, MS3, and MS3*. The main difference between MS3 and MS3* is the means of access used to perform the cleaning operations. Since for these five façade claddings the rope access is only suitable for cleaning operations; in MS3, the three maintenance activities (cleaning operations, minor interventions, and total replacement) are carried out using the same type of means of access. In MS3*, it is assumed that cleaning operations are always carried out by rope access and, because of that, for the remaining maintenance activities, the type of means of access used varies. On the other hand, for PS, rope access is also suitable for total replacement of the cladding. Therefore, only two maintenance strategies are analysed for PS: MS1 and MS4.

In Figures 2-7, maintenance costs (including inspection costs), at year 0, obtained for the different maintenance strategies and means of access, for the six façade claddings, are compared.

For a 150-year time horizon and a real discount rate of $6 \%$, the inspection costs are $8.33 € / \mathrm{m}^{2}$ (time interval between inspection of 2 years) for PS, $5.39 € / \mathrm{m}^{2}$ (interval of 3 years) for RF and ETICS, $3.92 € / \mathrm{m}^{2}$ (interval of 4 years) for CTS and ACT, and $3.04 € / \mathrm{m}^{2}$ (interval of 5 years) for NSC. 


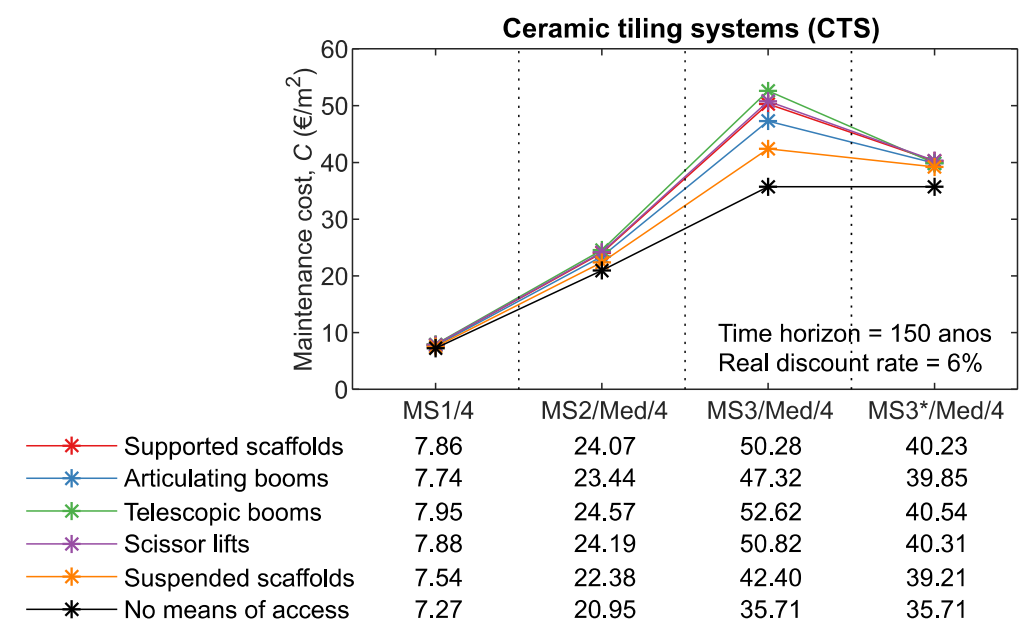

Figure 2. Sensitivity analysis of the different means of access in CTS maintenance strategy costs for a time horizon of 150 years.

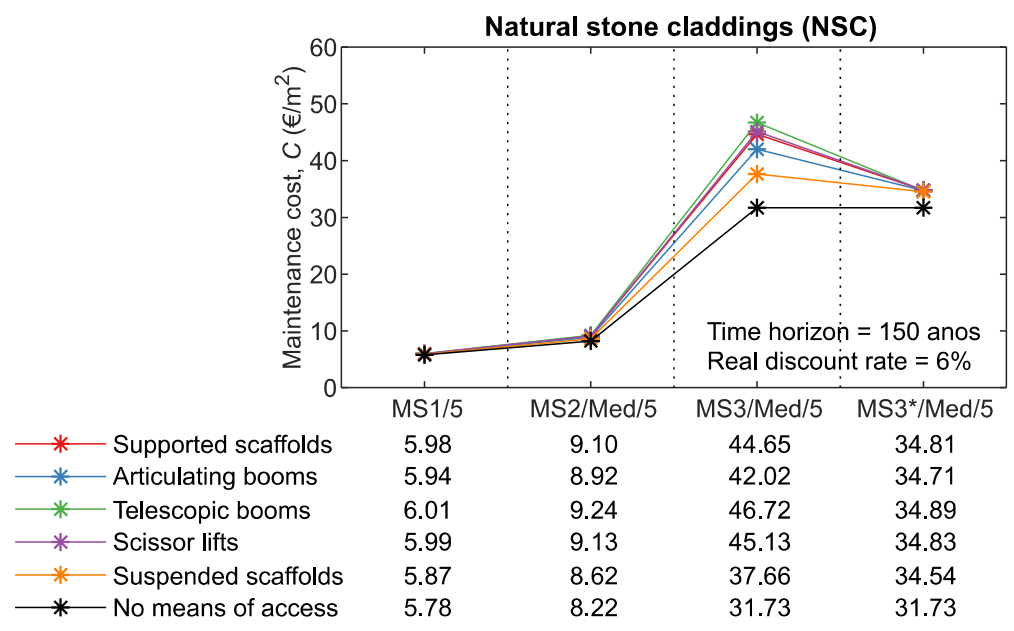

Figure 3. Sensitivity analysis of the different means of access in NSC maintenance strategy costs for a time horizon of 150 years.

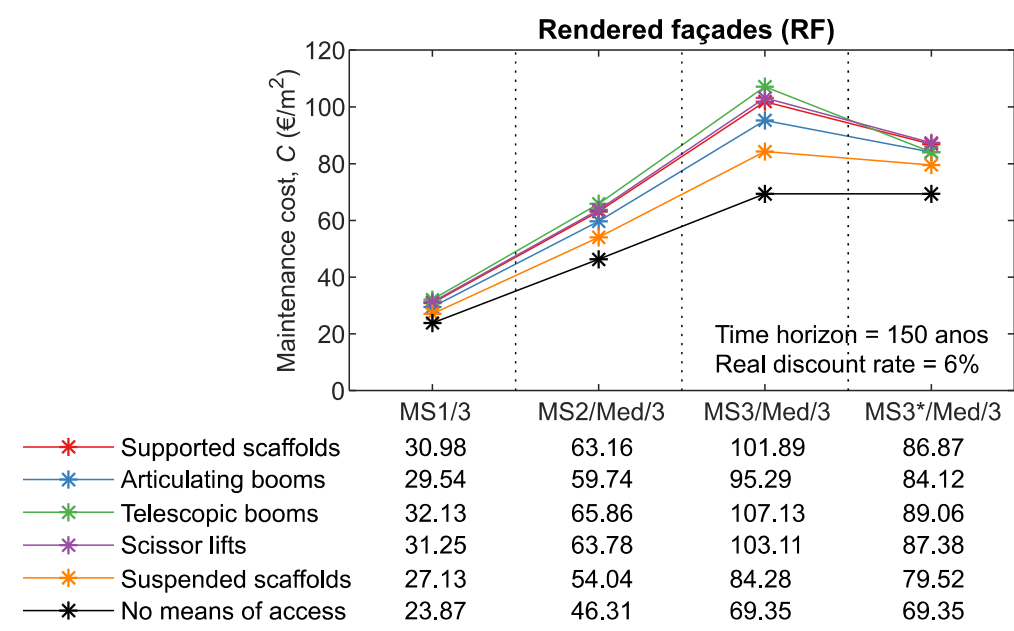

Figure 4. Sensitivity analysis of the different means of access in RF maintenance strategy costs for a time horizon of 150 years. 


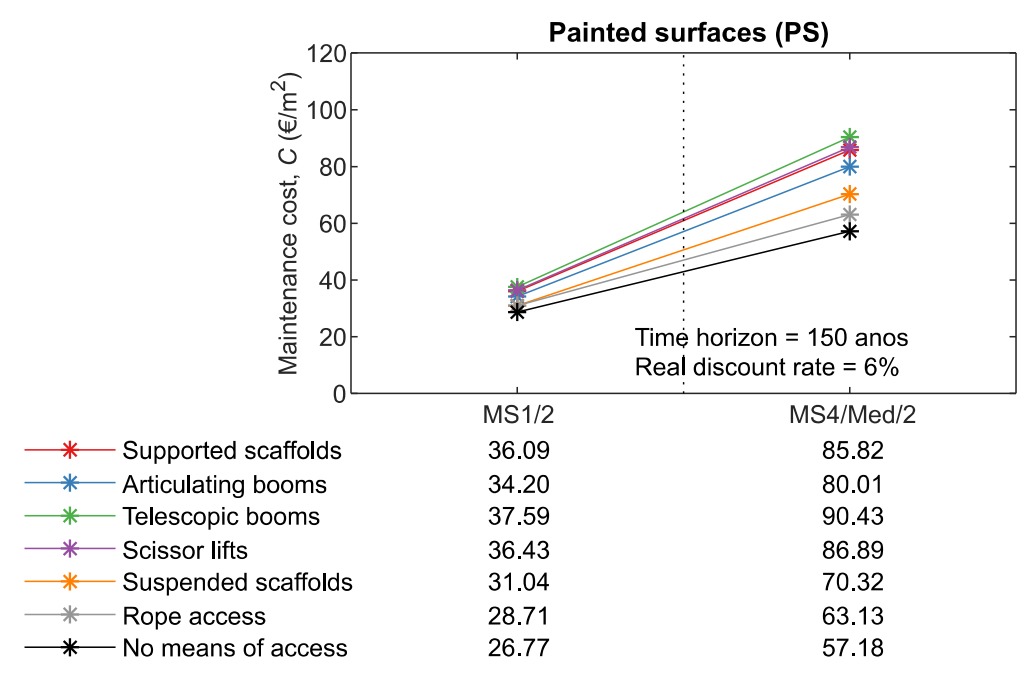

Figure 5. Sensitivity analysis of the different means of access in PS maintenance strategy costs for a time horizon of 150 years.

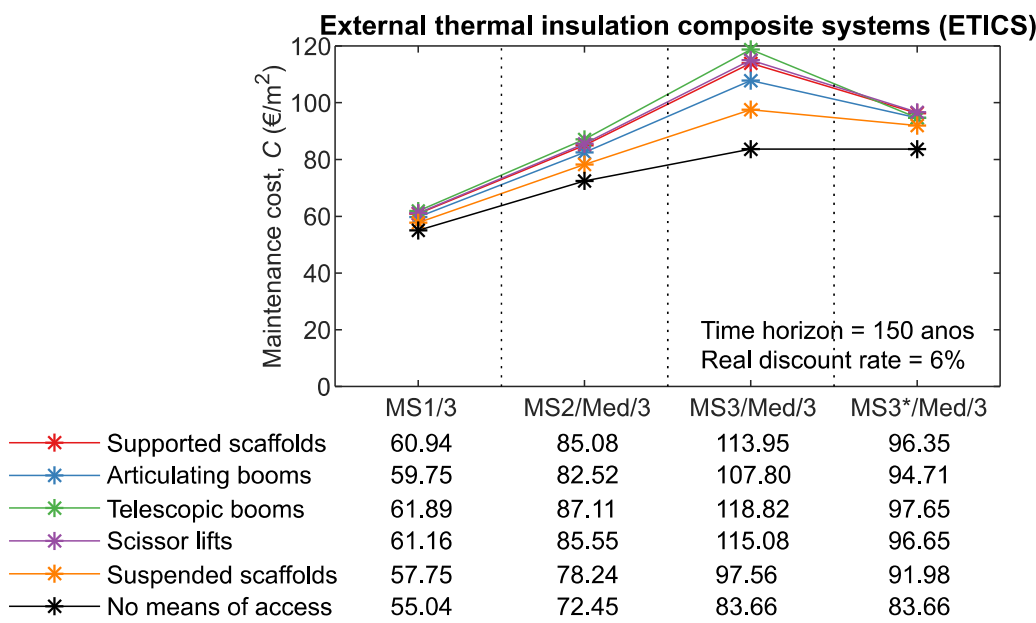

Figure 6. Sensitivity analysis of the different means of access in ETICS maintenance strategy costs for a time horizon of 150 years.

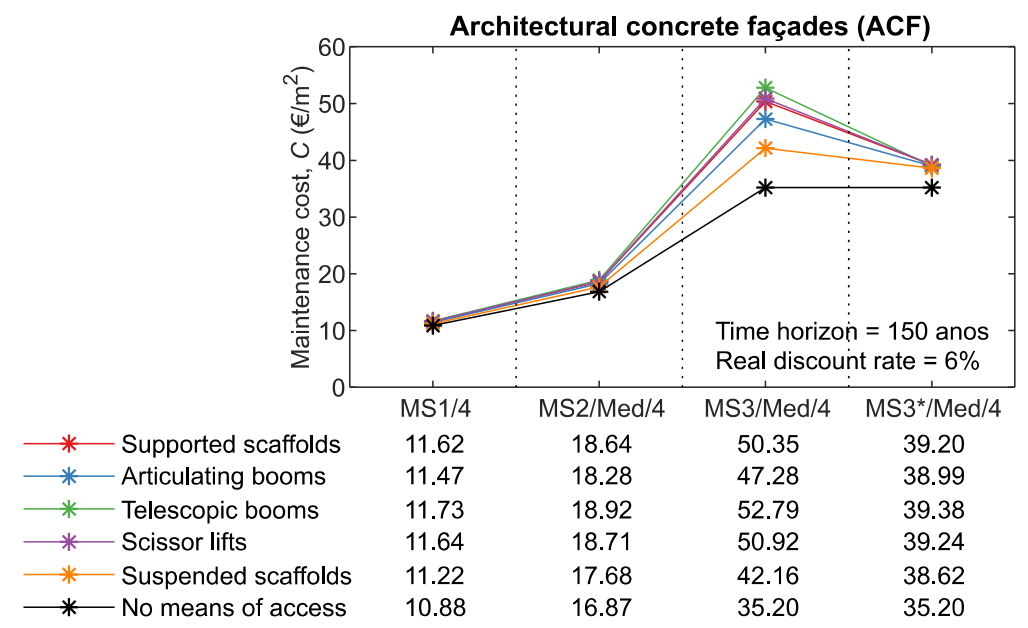

Figure 7. Sensitivity analysis of the different means of access in ACF maintenance strategy costs for a time horizon of 150 years. 
Generally, the results obtained in the sensitivity analysis are in line with what would be expected. Firstly, as maintenance strategies become more complete (higher number of different types of interventions), there is an increase in maintenance costs. Secondly, the maintenance costs and the unit cost of the means of access (Table 1) have a direct relationship. Maintenance strategies combined with the most economical means of access correspond to the most economical options. However, the usefulness of this analysis is to quantify the savings, over the time horizon, when specific access equipment is not needed. Comparing with the different means of access and claddings, maintenance costs present an average reduction between 10\% (for NSC) and $26 \%$ (for PS). When crossing this information with the service life and number of intervention values [30], the results reveal that the reduction on maintenance costs is greater for claddings and maintenance strategies subjected to a higher number of interventions during the time horizon.

For example, the impact on maintenance costs on MS3 is higher than on MS2 or MS1 (the number of interventions increases with the complexity of the maintenance strategy). In addition, for RF and PS (claddings with reduced service life and, consequently, higher number of interventions during the time horizon), the impact on maintenance costs is higher than for the remaining claddings (CTS, NSC, ETICS, and ACF). For RF/MS3 and PS/MS4, the costs of the means of access can represent a third of the maintenance costs. Furthermore, it is also found that the use of rope access to carry out cleaning operations has a significant impact on maintenance costs. For the 150-year time horizon, there is an average reduction of $20 \%$ in maintenance costs for CTS, NSC, and ACF, and $15 \%$ for RF and ETICS.

\section{Multi-Criteria Analysis}

In the same way as choosing the materials to be implemented in the façades, the types of maintenance strategies to be adopted, as well as the level of interventions and the time interval between inspections, the owners or managers always have the last word when it comes to deciding on the means of access to be used. Although the decision process is subjective, this decision must include different parameters, such as budget limitations, aesthetic appearance, target performance level, local constraints, the social and economic context of the building, among other criteria. Multi-criteria analysis is a useful tool to aid decision makers to coherently manage the available information. It can be used to identify a single option, to select a shortlist of options for future detailed appraisal, or to differentiate between acceptable and unacceptable possibilities [35]. The multi-criteria analysis allows ranking the different alternatives according to the criteria defined. In this study, an additive aggregation approach with compensatory rationality is implemented [36], as seen in Equation (5).

$$
X_{i}=\sum_{j=1}^{m} \lambda_{j} \times x_{i j}, \text { with } \sum_{j=1}^{m} \lambda_{j}=1,
$$

where $X_{i}$ is the global ranking of the alternative $i, \lambda_{j}$ is the weight of the criterion $j$, and $x_{i j}$ is the standardized classification of alternative $i$ according to criterion $j$. The different scales in the different criteria are standardized by Equation (6) for an increased order of preference and by Equation (7) for a decreased order of preference [37].

$$
\begin{aligned}
& x_{i j}=\frac{X_{i j}-\min X_{i j}}{\max X_{i j}-\min X_{i j}}, \\
& x_{i j}=\frac{\max X_{i j}-X_{i j}}{\max X_{i j}-\min X_{i j}},
\end{aligned}
$$

where $X_{i j}$ is the classification of alternative $i$ according to criterion $j$, and $\min X_{i j}$ and $\max$ $X_{i j}$ are the minimum and maximum value of criterion $j$, respectively.

From the individual analysis and comparison of criteria, it is difficult to identify the most and least advantageous alternative from all points of view. The strengths and 
weaknesses differ according to the criterion analysed. In this sense, for the different façade claddings, the different maintenance strategies and means of access (options) are globally classified in terms of durability (service life), performance (efficiency index), and maintenance costs. Consequently, four scenarios, considering three criteria (efficiency index, maintenance costs, and total replacements), are analysed. The four scenarios are: (1) the same importance is given to the three criteria; (2) a higher emphasis is given to the efficiency index; (3) a higher emphasis is given to the maintenance costs; and (4) a higher emphasis is given to the number of total replacements over the time horizon. Data referring to the efficiency index and total number of replacements can be consulted in Ferreira et al. [30]. In Tables 3 and 4, the results obtained in the multi-criteria analysis are presented.

Table 3. Multi-criteria analysis.

\begin{tabular}{|c|c|c|c|c|c|c|c|c|c|c|c|c|c|}
\hline \multicolumn{2}{|c|}{ Façade Claddings } & CTS & NSC & RF & PS & ETICS & ACF & CTS & NSC & RF & PS & ETICS & $\overline{\mathrm{ACF}}$ \\
\hline & Scenario & \multicolumn{6}{|c|}{1} & \multicolumn{6}{|c|}{2} \\
\hline \multicolumn{2}{|c|}{$\begin{array}{c}\text { Scenarıo } \\
\text { Criteria }\end{array}$} & \multicolumn{12}{|c|}{ Weight, $\lambda_{i}$} \\
\hline \multirow{3}{*}{\multicolumn{2}{|c|}{$\begin{array}{l}\text { Efficiency index } \\
\text { Maintenance costs } \\
\text { Total replacements }\end{array}$}} & \multirow{2}{*}{\multicolumn{6}{|c|}{$\begin{array}{l}33.3 \% \\
33.3 \%\end{array}$}} & \multicolumn{6}{|c|}{$50.0 \%$} \\
\hline & & & & & & & & \multicolumn{6}{|c|}{$25.0 \%$} \\
\hline & & \multicolumn{3}{|c|}{$33.3 \%$} & & & & \multicolumn{6}{|c|}{$25.0 \%$} \\
\hline MS & Means of access & & & & & Stand & dized & obal ra & $\operatorname{ng}, x_{i}$ & & & & \\
\hline \multirow{7}{*}{$\sum^{\bar{n}}$} & SS & 0.00 & 0.00 & 0.01 & 0.01 & 0.01 & 0.00 & 0.00 & 0.00 & 0.01 & 0.01 & 0.01 & 0.00 \\
\hline & $\mathrm{AB}$ & 0.00 & 0.00 & 0.02 & 0.03 & 0.02 & 0.00 & 0.00 & 0.00 & 0.01 & 0.02 & 0.01 & 0.00 \\
\hline & $\mathrm{TB}$ & 0.00 & 0.00 & 0.00 & 0.00 & 0.00 & 0.00 & 0.00 & 0.00 & 0.00 & 0.00 & 0.00 & 0.00 \\
\hline & SL & 0.00 & 0.00 & 0.01 & 0.01 & 0.01 & 0.00 & 0.00 & 0.00 & 0.00 & 0.01 & 0.00 & 0.00 \\
\hline & SpS & 0.01 & 0.00 & 0.04 & 0.06 & 0.04 & 0.01 & 0.00 & 0.00 & 0.02 & 0.04 & 0.02 & 0.01 \\
\hline & RA & - & - & - & 0.08 & - & - & - & - & - & 0.05 & - & - \\
\hline & NMA & 0.01 & 0.00 & 0.06 & 0.10 & 0.06 & 0.01 & 0.01 & 0.00 & 0.04 & 0.06 & 0.04 & 0.01 \\
\hline \multirow{7}{*}{$\sum^{N}$} & SS & 0.75 & 0.99 & 0.71 & - & 0.59 & 0.97 & 0.69 & 0.92 & 0.69 & - & 0.58 & 0.93 \\
\hline & $\mathrm{AB}$ & 0.76 & 0.99 & 0.74 & - & 0.61 & 0.98 & 0.69 & 0.92 & 0.70 & - & 0.60 & 0.93 \\
\hline & TB & 0.74 & 0.98 & 0.69 & - & 0.57 & 0.97 & 0.68 & 0.92 & 0.67 & - & 0.57 & 0.92 \\
\hline & $\mathrm{SL}$ & 0.75 & 0.98 & 0.71 & - & 0.58 & 0.97 & 0.69 & 0.92 & 0.68 & - & 0.58 & 0.92 \\
\hline & SpS & 0.77 & 0.99 & 0.78 & - & 0.65 & 0.99 & 0.70 & 0.92 & 0.73 & - & 0.62 & 0.93 \\
\hline & RA & - & - & - & - & - & - & - & - & - & - & - & - \\
\hline & NMA & 0.80 & 1.00 & 0.84 & - & 0.71 & 1.00 & 0.72 & 0.93 & 0.77 & - & 0.66 & 0.94 \\
\hline \multirow{7}{*}{$\sum^{\infty}$} & SS & 0.77 & 0.71 & 0.75 & - & 0.71 & 0.72 & 0.87 & 0.87 & 0.85 & - & 0.82 & 0.85 \\
\hline & $\mathrm{AB}$ & 0.82 & 0.76 & 0.80 & - & 0.77 & 0.77 & 0.89 & 0.89 & 0.88 & - & 0.86 & 0.88 \\
\hline & TB & 0.73 & 0.68 & 0.71 & - & 0.67 & 0.68 & 0.84 & 0.85 & 0.82 & - & 0.79 & 0.83 \\
\hline & SL & 0.76 & 0.71 & 0.74 & - & 0.70 & 0.71 & 0.86 & 0.86 & 0.84 & - & 0.81 & 0.85 \\
\hline & SpS & 0.89 & 0.83 & 0.88 & - & 0.87 & 0.85 & 0.94 & 0.94 & 0.93 & - & 0.92 & 0.93 \\
\hline & RA & - & - & - & - & - & - & - & - & - & - & - & - \\
\hline & NMA & 1.00 & 0.93 & 1.00 & - & 1.00 & 0.96 & 1.00 & 1.00 & 1.00 & - & 1.00 & 1.00 \\
\hline \multirow{7}{*}{ 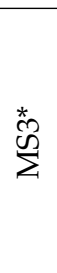 } & SS & 0.93 & 0.88 & 0.86 & - & 0.88 & 0.89 & 0.96 & 0.97 & 0.92 & - & 0.93 & 0.96 \\
\hline & $\mathrm{AB}$ & 0.93 & 0.88 & 0.89 & - & 0.90 & 0.90 & 0.96 & 0.97 & 0.93 & - & 0.93 & 0.96 \\
\hline & TB & 0.92 & 0.87 & 0.85 & - & 0.87 & 0.89 & 0.96 & 0.97 & 0.91 & - & 0.92 & 0.96 \\
\hline & SL & 0.93 & 0.88 & 0.86 & - & 0.88 & 0.89 & 0.96 & 0.97 & 0.92 & - & 0.92 & 0.96 \\
\hline & SpS & 0.94 & 0.88 & 0.92 & - & 0.92 & 0.90 & 0.97 & 0.97 & 0.95 & - & 0.95 & 0.97 \\
\hline & RA & - & - & - & - & - & - & - & - & - & - & - & - \\
\hline & NMA & 1.00 & 0.93 & 1.00 & - & 1.00 & 0.96 & 1.00 & 1.00 & 1.00 & - & 1.00 & 1.00 \\
\hline \multirow{7}{*}{$\sum^{\text {W }}$} & SS & - & - & - & 0.73 & - & - & - & - & - & 0.83 & - & - \\
\hline & $\mathrm{AB}$ & - & - & - & 0.79 & - & - & - & - & - & 0.87 & - & - \\
\hline & $\mathrm{TB}$ & - & - & - & 0.69 & - & - & - & - & - & 0.81 & - & - \\
\hline & SL & - & - & - & 0.72 & - & - & - & - & - & 0.83 & - & - \\
\hline & SpS & - & - & - & 0.88 & - & - & - & - & - & 0.92 & - & - \\
\hline & RA & - & - & - & 0.94 & - & - & - & - & - & 0.97 & - & - \\
\hline & NMA & - & - & - & 1.00 & - & - & - & - & - & 1.00 & - & - \\
\hline
\end{tabular}

Legend: SS—supported scaffolds; AR—articulated booms; TB—telescopic booms; SL—scissor lifts; SpS—suspended scaffolds; RA—rope access; NMA-no means of access. 
Table 4. Multi-criteria analysis continuation.

\begin{tabular}{|c|c|c|c|c|c|c|c|c|c|c|c|c|c|}
\hline \multicolumn{2}{|c|}{ Façade Claddings } & CTS & NSC & RF & PS & ETICS & ACF & CTS & NSC & RF & PS & ETICS & ACF \\
\hline \multicolumn{2}{|c|}{ Scenario } & \multicolumn{6}{|c|}{3} & \multicolumn{6}{|c|}{4} \\
\hline & Criteria & \multicolumn{12}{|c|}{ Weight, $\lambda_{i}$} \\
\hline \multirow{3}{*}{\multicolumn{2}{|c|}{$\begin{array}{c}\text { Efficiency index } \\
\text { Maintenance costs } \\
\text { Total replacements }\end{array}$}} & \multicolumn{6}{|c|}{$25.0 \%$} & \multicolumn{6}{|c|}{$25.0 \%$} \\
\hline & & \multicolumn{6}{|c|}{$50.0 \%$} & \multicolumn{6}{|c|}{$25.0 \%$} \\
\hline & & \multicolumn{6}{|c|}{$25.0 \%$} & \multicolumn{6}{|c|}{$50.0 \%$} \\
\hline MS & Means of access & & & & & Stand & rdized & obal rc & $\mathrm{ng}, x_{i}$ & & & & \\
\hline \multirow{7}{*}{$\sum^{\bar{N}}$} & SS & 0.01 & 0.00 & 0.02 & 0.03 & 0.02 & 0.00 & 0.00 & 0.00 & 0.01 & 0.01 & 0.01 & 0.00 \\
\hline & $\mathrm{AB}$ & 0.01 & 0.00 & 0.05 & 0.08 & 0.05 & 0.01 & 0.00 & 0.00 & 0.01 & 0.02 & 0.01 & 0.00 \\
\hline & TB & 0.00 & 0.00 & 0.00 & 0.00 & 0.00 & 0.00 & 0.00 & 0.00 & 0.00 & 0.00 & 0.00 & 0.00 \\
\hline & SL & 0.00 & 0.00 & 0.02 & 0.03 & 0.02 & 0.00 & 0.00 & 0.00 & 0.00 & 0.01 & 0.00 & 0.00 \\
\hline & SpS & 0.02 & 0.00 & 0.11 & 0.15 & 0.10 & 0.02 & 0.00 & 0.00 & 0.02 & 0.04 & 0.02 & 0.01 \\
\hline & RA & - & - & & 0.20 & - & - & - & - & - & 0.05 & - & - \\
\hline & NMA & 0.04 & 0.01 & 0.17 & 0.25 & 0.16 & 0.03 & 0.01 & 0.00 & 0.04 & 0.06 & 0.04 & 0.01 \\
\hline \multirow{7}{*}{$\sum^{\tilde{\Sigma}}$} & SS & 0.83 & 0.97 & 0.64 & - & 0.46 & 0.94 & 0.76 & 0.96 & 0.76 & - & 0.65 & 0.94 \\
\hline & $\mathrm{AB}$ & 0.87 & 0.98 & 0.72 & - & 0.53 & 0.95 & 0.77 & 0.96 & 0.77 & - & 0.67 & 0.94 \\
\hline & TB & 0.81 & 0.96 & 0.59 & - & 0.42 & 0.93 & 0.76 & 0.96 & 0.74 & - & 0.64 & 0.94 \\
\hline & SL & 0.83 & 0.97 & 0.63 & - & 0.45 & 0.94 & 0.76 & 0.96 & 0.75 & - & 0.65 & 0.94 \\
\hline & SpS & 0.92 & 0.99 & 0.84 & - & 0.63 & 0.97 & 0.78 & 0.97 & 0.80 & - & 0.70 & 0.95 \\
\hline & RA & - & - & - & - & - & - & - & - & - & - & - & - \\
\hline & NMA & 1.00 & 1.00 & 1.00 & - & 0.77 & 1.00 & 0.79 & 0.97 & 0.84 & - & 0.73 & 0.96 \\
\hline \multirow{7}{*}{$\sum^{\infty}$} & SS & 0.16 & 0.08 & 0.29 & - & 0.28 & 0.11 & 0.87 & 0.87 & 0.85 & - & 0.82 & 0.85 \\
\hline & $A B$ & 0.32 & 0.17 & 0.43 & - & 0.43 & 0.22 & 0.89 & 0.89 & 0.88 & - & 0.86 & 0.88 \\
\hline & $\mathrm{TB}$ & 0.04 & 0.01 & 0.17 & - & 0.16 & 0.03 & 0.84 & 0.85 & 0.82 & - & 0.79 & 0.83 \\
\hline & SL & 0.13 & 0.06 & 0.26 & - & 0.25 & 0.09 & 0.86 & 0.86 & 0.84 & - & 0.81 & 0.85 \\
\hline & SpS & 0.59 & 0.32 & 0.66 & - & 0.67 & 0.40 & 0.94 & 0.94 & 0.93 & - & 0.92 & 0.93 \\
\hline & RA & - & - & - & - & - & - & - & - & - & - & - & - \\
\hline & NMA & 0.95 & 0.52 & 0.97 & - & 1.00 & 0.64 & 1.00 & 1.00 & 1.00 & - & 1.00 & 1.00 \\
\hline \multirow{7}{*}{ 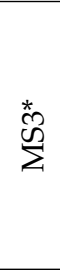 } & SS & 0.70 & 0.42 & 0.60 & - & 0.70 & 0.50 & 0.96 & 0.97 & 0.92 & - & 0.93 & 0.96 \\
\hline & $A B$ & 0.72 & 0.42 & 0.66 & - & 0.74 & 0.51 & 0.96 & 0.97 & 0.93 & - & 0.93 & 0.96 \\
\hline & TB & 0.69 & 0.41 & 0.56 & - & 0.67 & 0.49 & 0.96 & 0.97 & 0.91 & - & 0.92 & 0.96 \\
\hline & SL & 0.70 & 0.42 & 0.59 & - & 0.69 & 0.50 & 0.96 & 0.97 & 0.92 & - & 0.92 & 0.96 \\
\hline & SpS & 0.76 & 0.43 & 0.76 & - & 0.80 & 0.52 & 0.97 & 0.97 & 0.95 & - & 0.95 & 0.97 \\
\hline & RA & - & - & - & - & - & - & - & - & - & - & - & - \\
\hline & NMA & 0.95 & 0.52 & 0.97 & - & 1.00 & 0.64 & 1.00 & 1.00 & 1.00 & - & 1.00 & 1.00 \\
\hline \multirow{7}{*}{$\sum^{\stackrel{5}{\Sigma}}$} & SS & - & - & - & 0.35 & - & - & - & - & - & 0.83 & - & - \\
\hline & $\mathrm{AB}$ & - & - & - & 0.48 & - & - & - & - & - & 0.87 & - & - \\
\hline & TB & - & - & - & 0.25 & - & - & - & - & - & 0.81 & - & - \\
\hline & SL & - & - & - & 0.33 & - & - & - & - & - & 0.83 & - & - \\
\hline & SpS & - & - & - & 0.70 & - & - & - & - & - & 0.92 & - & - \\
\hline & RA & - & - & - & 0.86 & - & - & - & - & - & 0.97 & - & - \\
\hline & NMA & - & - & - & 1.00 & - & - & - & - & - & 1.00 & - & - \\
\hline
\end{tabular}

Legend: SS—supported scaffolds; AR—articulated booms; TB—telescopic booms; SL—scissor lifts; SpS—suspended scaffolds; RA—rope access; NMA—no means of access.

In a first analysis, the results reveal, for all façade claddings, that the alternatives where there is no need for means of access are the most advantageous. Therefore, the results confirm that the planning of accessibility to the different building envelope elements, in the design stage, can have a significant influence on maintenance costs over time. On the other hand, if the use of temporary means of access is indispensable (it should be predicted at design stage also in terms of costs), the results suggest that selecting rope access (for cleaning operations and total replacement of the painted surface, only in maintenance works where technical quality is guaranteed) and/or suspended scaffolds (for other types of interventions) are the most advantageous alternatives. 
Concerning the least advantageous alternatives, the results show that MS1 using telescopic booms is the worst option. However, the results reveal that the correct choice of means of access depends on several factors, such as building envelope, safety, interference with users, proximity to road traffic, structural limitations of the building, weather conditions, load capacity, and/or building volume/shape.

On the other hand, the results also show that it is advantageous to opt for more complete maintenance strategies (MS2, MS3, and/or MS4), while MS1 is the least beneficial one. For example, for CTS and RF, in three of the four scenarios analysed, MS3 is the most advantageous alternative. This position only changes to MS2 if more emphasis is placed on maintenance costs (scenario 3). For NSC and ACF, in scenarios 1 and 3, MS2 is the most advantageous alternative, while MS3 is the most beneficial in scenarios 2 and 4. For ETICS, MS3 is the most advantageous alternative for the four scenarios. Finally, for PS, MS4 is the most advantageous alternative for the four scenarios.

Finally, the weights in Tables 3 and 4 are indicative. The weight can be influenced by several factors, such as location, economic context, and owner's requirements, among others. However, subjectivity can be reduced through expert judgements or through other multi-criteria decision methodologies, such as the analytic hierarchy process (AHP), which can help to define priorities through a process of pair-wise comparisons $[38,39]$.

\section{Discussion/General Recommendations}

From the results, some guidelines can be provided, which can help decision makers to make more rational and informed choices, based on objective criteria. However, the decision process is always influenced by subjective criteria, which depend on the experience and individual perceptions of decision makers. These criteria are practically impossible to model. However, on the other hand, objective criteria can be evaluated depending on the requirements of decision makers. Furthermore, it should be mentioned that all alternatives considered in this study are technically and economically valid. Thus, they can all be successfully applied to building envelope elements.

In a global analysis, the adoption of preventive maintenance activities (such as cleaning operations, local repairs, and local replacements) is beneficial. These actions allow increasing the durability of the façade claddings and reducing their physical degradation. Moreover, the risk to users and owners is reduced and, consequently, users' satisfaction and the aesthetic perception of cities are improved. In Table 5, general recommendations of the most viable maintenance strategies to be implemented in the different façade claddings are presented. There, together with the identification of the most advantageous maintenance strategy and means of access for each façade cladding, the values of the essential parameters to be considered in this analysis are presented. These parameters are:

- The service life: the end of the service life of the façade claddings is reached when the element reaches the degradation condition D;

- The efficiency index: this value ranges between 0 and 1 . The higher the EI value, the longer the element remains in the best degradation conditions (A, B, and C) during the time horizon (period of study);

- The annualized maintenance cost: corresponds to the division between the life-cycle cost (includes inspection and maintenance costs) of the maintenance strategy of the element in year 0 , by the time horizon;

- The total number of replacements: corresponds to the average number of total replacements to which element is subject during the time horizon. 
Table 5. Unit costs, at year 0 , for the different maintenance activities without the means of access costs.

\begin{tabular}{|c|c|c|c|c|c|}
\hline $\begin{array}{l}\text { Façade } \\
\text { Cladding }\end{array}$ & $\begin{array}{c}\text { Maintenance } \\
\text { Strategy/Means of Access }\end{array}$ & $\begin{array}{l}\text { Service Life } \\
\text { (Years) }\end{array}$ & $\begin{array}{l}\text { Efficiency } \\
\text { Index }\end{array}$ & $\begin{array}{c}\text { Annualized } \\
\text { Maintenance } \\
\text { Costs }\left(€ / \mathrm{m}^{2} / \text { Year }\right)\end{array}$ & $\begin{array}{l}\text { Total Number of } \\
\text { Replacements }\end{array}$ \\
\hline CTS & $\begin{array}{c}\text { MS3 }^{*} \\
\text { CO: Rope access } \\
\text { MI/TR: Suspended scaffolds } \\
\text { MS2 }\end{array}$ & 108 & 0.95 & 0.63 & 0.9 \\
\hline NSC & $\begin{array}{c}\text { CO: Rope access } \\
\text { MI/TR: Suspended scaffolds } \\
\text { MS3* }\end{array}$ & 148 & 0.94 & 0.97 & 0.5 \\
\hline RF & $\begin{array}{c}\text { CO: Rope access } \\
\text { MI/TR: Suspended scaffolds }\end{array}$ & 33 & 0.96 & 0.69 & 3.9 \\
\hline PS & $\begin{array}{c}\text { MS4 } \\
\text { CO/TR: Rope access } \\
\text { MS3 }^{*}\end{array}$ & 17 & 0.93 & 0.54 & 7.9 \\
\hline ETICS & $\begin{array}{c}\text { CO: Rope access } \\
\text { MI/TR: Suspended scaffolds } \\
\text { MS2 }\end{array}$ & 44 & 0.92 & 1.14 & 2.9 \\
\hline $\mathrm{ACF}$ & $\begin{array}{c}\text { CO: Rope access } \\
\text { MI/TR: Suspended scaffolds }\end{array}$ & 120 & 0.94 & 0.81 & 0.9 \\
\hline
\end{tabular}

The service life, efficiency index, and total number of total replacements can be consulted in Ferreira et al. [30]. Based on that, it is suggested that MS3 is adopted to ceramic tiling systems (CTS), rendered façades (RF), and ETICS; MS2 is adopted to natural stone claddings (NSC) and architectural concrete façades (ACF); and MS4 is adopted to painted surfaces (PS). Regarding the means of access, the situation where there is no need for means of access is the most advantageous option. This result shows the relevance of having a maintenance plan and considering permanent means of access during the design stage or at least predict temporary means in the maintenance costs. If the building configuration requires the use of means of access, the results suggest opting for rope access in the case of carrying out cleaning operations (when technical viable) and replacing the painted surface and suspended scaffolds for the other types of maintenance activities (minor interventions and total replacement).

\section{Conclusions}

In this study, a sensitivity analysis of the impact of the means of access costs on the maintenance plans developed for building façade claddings is carried out. Based on this analysis, general recommendations for maintenance strategies are provided. The means of access costs vary between $2.12 € / \mathrm{m}^{2}$ (rope access) and $11.84 € / \mathrm{m}^{2}$ (telescopic boom). From the analysis, the results and trends on the viability of maintenance strategies, initially identified for supported scaffolds, are maintained for the other types of means of access. In other words, for any means of access, the maintenance costs increase with the complexity of the maintenance strategy. Furthermore, as expected, the lowest maintenance costs occur for the most economical means of access. The situation in which there is no need for means of access (i.e., when the means of access are considered during design stage) is the most economical, leading to an average maintenance cost reduction of $10 \%$ to $26 \%$ compared to other means of access.

For the situation in which the use of means of access is indispensable, the results suggest opting for rope access in the case of carrying out cleaning operations and replacing the painted surface and suspended scaffolds for the other types of maintenance activities (minor interventions and total replacement). The use of rope access to perform cleaning operations has a considerable impact on the maintenance costs. For a time horizon of 150 years, an average reduction between $15 \%$ and $20 \%$ is obtained. For the remaining means of access, in comparison with supported scaffolds, suspended scaffolds lead to an average 
reduction of $5 \%$ to $21 \%$; the articulated boom leads to an average reduction of $2 \%$ to $6 \%$; the telescopic boom leads to an average increase of $2 \%$ to $5 \%$; and the scissor lifts lead to an average increase of $1 \%$.

Based on these results, it is understood that the design of permanent means of access during the design stage may not be economically beneficial for all types of façade claddings. For instance, for a time horizon of 150 years, the average maintenance cost reduction for NSC is $10 \%$. Possibly, the design of the permanent means of access, their construction, and their maintenance over the same horizon may represent a greater burden for the owner/manager than the use of planning temporary means of access when necessary. In addition, façades with nobler coatings may be more difficult to incorporate permanent means of access into the architecture without considerably affecting the aesthetics. However, for façade claddings, such as rendered façades and painted surfaces, the percentage of the means of access in the maintenance costs is already considerable (on average $26 \%$ ). In these cases, considering permanent means of access can be a more economical solution.

The results of the multi-criteria analysis confirm that there are advantages in selecting more complete maintenance strategies when several criteria are weighed, in addition to costs. When the criteria are assessed individually, the optimal maintenance plan changes according to the assessed criterion. For example, if the main purpose is to increase the service life of the element, more complete maintenance plans considering cleaning operations and minor interventions are preferable. On the other hand, if the purpose is to reduce maintenance costs, simpler maintenance strategies (without preventive maintenance activities) are the most indicated, even though they lead to the elements having higher rates of degradation (or worse degradation conditions) throughout their life cycle and, consequently, higher risks. The multi-criteria analysis helps to evaluate the criteria in a multidimensional way and, therefore, establish a hierarchical scale of preference. The recommendations presented in this paper correspond to the analysis of the results obtained in the different multi-criteria analysis carried out. The results reveal that, when the criteria are evaluated globally, there is a preference for opting for more complete maintenance strategies, while MS1 represents the least beneficial option.

Finally, it should be mentioned that this methodology should be seen as a general guideline for evaluating the impact of the means of access in the maintenance plans of the building envelope elements. Each situation should be evaluated individually, since other criteria, scenarios and weights can be considered, depending on the decision makers' requirements. The choice of materials to be implemented in buildings, maintenance strategies, intervention levels, time intervals between inspections, and means of access always depends on the owners or managers and the results that they want to obtain based on all the available parameters (objective and/or subjective).

Author Contributions: Conceptualization, C.F., I.S.D., A.S., J.d.B. and I.F.-C.; methodology, C.F. and I.S.D.; software, C.F.; validation, C.F.; investigation, C.F., I.S.D., A.S., J.d.B. and I.F.-C.; writingoriginal draft preparation, C.F.; writing - review and editing, I.S.D., A.S., J.d.B. and I.F.-C.; project administration, A.S. and J.d.B.; funding acquisition, A.S. and J.d.B. All authors have read and agreed to the published version of the manuscript.

Funding: This research was funded by FCT (Portuguese Foundation for Science and Technology) through the project BestMaintenance-LowerRisks (PTDC/ECI-CON/29286/2017).

Data Availability Statement: The data presented in this study are available on request from the corresponding author.

Acknowledgments: The authors gratefully acknowledge the support of CERIS, from Instituto Superior Técnico, Universidade de Lisboa.

Conflicts of Interest: The authors declare no conflict of interest. 


\section{References}

1. De Silva, N.; Ranasinghe, M.; de Silva, C.R. Risk factors affecting building maintenance under tropical conditions. J. Financ. Manag. Prop. Constr. 2012, 17, 235-252. [CrossRef]

2. Cardini, E.; Sohn, E.C. Above and beyond: Access techniques for the assessment of buildings and structures. In Proceedings of the AEI 2013: Building Solutions for Architectural Engineering, State College, PA, USA, 3-5 April 2013.

3. Korolchenko, D.A.; Pham, N.T. Loads in rope access system when working at heights. In Proceedings of the 4th World Multidisciplinary Civil Engineering-Architecture-Urban Planning Symposium, Prague, Czech Republic, 18-22 June 2018.

4. Wu, S.; Lee, A.; Tah, J.H.M.; Aouad, G. The use of a multi-attribute tool for evaluating accessibility in buildings: The AHP approach. Facilities 2007, 25, 375-389. [CrossRef]

5. Kamya, B.M. Industrial rope access approach in the inspection and maintenance management of bridges. In Proceeding of the 5th International Conference on Bridge Management, Surrey, UK, 11-13 April 2005.

6. Marais, K.B.; Saleh, J.H. Beyond its cost, the value of maintenance: An analytical framework for capturing its net present value. Reliab. Eng. Syst. Saf. 2009, 94, 644-657. [CrossRef]

7. Grosso, R.; Mecca, U.; Moglia, G.; Prizzon, F.; Rebaudengo, M. Collecting built environment information using UAVs: Time and applicability in building inspection activities. Sustainability 2017, 12, 4731. [CrossRef]

8. Rebaudengo, M.; Piantanida, P. Maintenance of building: Italian examples of deviations between planned and incurred costs. In Proceedings of the 2nd International Conference on Reliability Engineering, Milan, Italy, 20-22 December 2017.

9. Kim, K.; Teizer, J. Automatic design and planning of scaffolding systems using building information modeling. Adv. Eng. Inform. 2014, 28, 66-80. [CrossRef]

10. El-Haram, M.A.; Horner, M.W. Factors affecting housing maintenance cost. J. Qual. Maint. Eng. 2002, 8, 115-123. [CrossRef]

11. Ferreira, C.; Silva, A.; de Brito, J.; Dias, I.S.; Flores-Colen, I. Definition of a condition-based model for natural stone claddings. J. Build. Eng. 2021, 33, 101643. [CrossRef]

12. Rajendran, S.; Gambatese, J. Risk and financial impacts of prevention through design solutions. Pract. Period. Struct. Des. Constr. 2013, 18, 67-72. [CrossRef]

13. Wang, F.; Tamura, Y.; Yoshida, A. Wind loads on clad scaffolding with different geometries and building opening ratios. J. Wind Eng. Ind. Aerodyn. 2013, 120, 37-50. [CrossRef]

14. Chew, Y.L.; Tan, P.P. Staining of Façades; World Scientific: Singapore, 2003.

15. Chew, Y.L. Maintainability of Facilities: Green FM for Building Professionals, 2nd ed.; Scientific Publishing Company: Singapore, 2016.

16. Vossoughi, H.; Siddiqui, R.I. Industrial rope access-An alternate means for inspection, maintenance, and repair of building facades and structures. In STP1444-EB Building Facade Maintenance, Repair, and Inspection; ASTM International: West Conshohocken, PA, USA, 2004.

17. McCann, M. Deaths in construction related to personnel lifts, 1992-1999. J. Saf. Res. 2003, 34, 507-514. [CrossRef]

18. Dogan, E.; Yurdusev, M.A.; Yildizel, S.A.; Calis, G. Investigation of scaffolding accident in a construction site: A case study analysis. Eng. Fail. Anal. 2021, 120, 105108. [CrossRef]

19. Sevim, B.; Bekiroglu, S.; Arslan, G. Experimental evaluation of tie bar effects on structural behavior of suspended scaffolding systems. Adv. Steel Constr. 2017, 13, 62-77.

20. Stay, K. Rope access for inspection, testing and maintenance of industrial structures. J. Prot. Coat. Linings 2018, 35 , 44-48.

21. Hold, S. Rope access for inspection and maintenance. Proc. Inst. Civ. Eng. Munic. Eng. 1997, 121, 206-211. [CrossRef]

22. Pan, C.S.; Hoskin, A.; McCann, M.; Lin, M.L.; Fearn, K.; Keane, P. Aerial lift fall injuries: A surveillance and evaluation approach for targeting prevention activities. J. Saf. Res. 2007, 38, 617-625.

23. Ferreira, C.; Neves, L.C.; Silva, A.; de Brito, J. Stochastic maintenance models for ceramic claddings. Struct. Infrastruct. Eng. 2020, 16, 247-265. [CrossRef]

24. Bordalo, R.; de Brito, J.; Gaspar, P.L.; Silva, A. Service life prediction modelling of adhesive ceramic tiling systems. Build. Res. Inf. 2011, 39, 66-78.

25. Silva, A.; de Brito, J.; Gaspar, P.L. Service life prediction model applied to natural stone wall claddings (directly adhered to the substrate). Constr. Build. Mater. 2011, 25, 3674-3684.

26. Gaspar, P.L.; de Brito, J. Quantifying environmental effects on cement-rendered facades: A comparison between different degradation indicators. Build. Environ. 2008, 43, 1818-1828. [CrossRef]

27. Chai, C.; de Brito, J.; Gaspar, P.L.; Silva, A. Predicting the service life of exterior wall painting: Techno-economic analysis of alternative maintenance strategies. J. Constr. Eng. Manag. 2014, 140, 04013057. [CrossRef]

28. Ximenes, S.; de Brito, J.; Gaspar, P.L.; Silva, A. Modelling the degradation and service life of ETICS in external walls. Mater. Struct. 2015, 48, 2235-2249. [CrossRef]

29. Serralheiro, M.I.; de Brito, J.; Silva, A. Methodology for service life prediction of architectural concrete facades. Constr. Build. Mater. 2017, 133, 261-274. [CrossRef]

30. Ferreira, C.; Dias, I.S.; Silva, A.; de Brito, J.; Flores-Colen, I. Criteria for selection of cladding systems based on their maintainability. J. Build. Eng. 2021, 39, 102260. [CrossRef]

31. ISO 15686-5. Buildings and Constructed Assets—Service Life Planning_Part 5: Whole Life Costing; International Organization for Standardization (ISO): Geneva, Switzerland, 2012. 
32. Langdon, D. Life Cycle Costing (LCC) as a Contribution to Sustainable Construction. Guidance on the Use of the LCC Methodology and Its Application in Public Procurement; Davis Langdon Management Consulting: London, UK, 2007.

33. Sánchez-Silva, M.; Klutke, G.-A. Reliability and Life-Cycle Analysis of Deteriorating Systems; Springer International Publishing: Zurich, Switzerland, 2016.

34. CYPE Price Generator. Available online: http:/ /www.geradordeprecos.info/ (accessed on 12 October 2020).

35. Dodgson, J.S.; Spackman, M.; Pearman, A.; Phillips, L.D. Multi-Criteria Analysis: A Manual; Department for Communities and Local Government: London, UK, 2009.

36. Cochran, J.K.; Chen, H.N. Fuzzy multi-criteria selection of object-oriented simulation software for production system analysis. Comput. Oper. Res. 2005, 32, 153-168. [CrossRef]

37. Silva, A.; de Brito, J.; Gaspar, P.L. Methodologies for Service Life Prediction of Buildings: With a Focus on Façade Claddings; Springer International Publishing: Zurich, Switzerland, 2016.

38. Arunraj, N.S.; Maiti, J. Risk-based maintenance policy selection using AHP and goal programming. Saf. Sci. 2010, 48, 238-247. [CrossRef]

39. Bertolini, M.; Bevilacqua, M. A combined goal programming-AHP approach to maintenance selection problem. Reliab. Eng. Syst. Saf. 2006, 91, 839-848. [CrossRef] 